\title{
Valor da aspartato transaminase no diagnóstico precoce da intoxicação crônica por cobre em ovinos
}

\author{
Value of the ast on the early diagnosis of chronic \\ cooper poisoning in sheep
}

\author{
Roseli de Oliveira Möllerke, ${ }^{\star}$ Eduardo Amato Bernhard**
}

\begin{abstract}
Resumo
Através da medida da aspartato transaminase (E.C.2.6.1.1.) (AST), foi realizado, por dois anos consecutivos, o controle de 110 ovinos expostos em feira internacional, procurando-se detectar animais, prestes a desencadear crise hemolítica, devida a intoxicação crônica por cobre (ICC).

No primeiro ano, ocorreram óbitos por ICC, e a medida da AST revelou taxas elevadas no sangue dos animais. Metade dos animais que apresentaram niveis de AST superiores a $600 \mathrm{UI} / \mathrm{l}$ morreram em crise hemolítica. Sugere-se que o manejo, 0 estresse da viagem e da feira, aliados à grande quantidade de ração ingerida, desencadearam a crise. No segundo ano, não ocorreram mortes dos animais e constatou-se a diminuição dos níveis enzimáticos de AST no sangue. Os dados obtidos sugerem que a medida da AST é um bom indicador do desencadeamento da crise hemolítica em ovinos submetidos a dietas rica em cobre.
\end{abstract}

Palavras-chave: cobre, intoxicação ovinos, aspartato transaminase.

\begin{abstract}
The serum level of aspartate aminotransferase (AST) was assayed two consecutive years on 110 sheep that were shown at an International Agricultural Show to detect the risk of haemolytic crisis due to chronic copper poisoning (CCP).

In the first year, cases of CCP did occur and high levels of AST were observed on the serum of affected animals. Fifty percent of the animals with AST serum level superior to $600 \mathrm{UI} / \mathrm{L}$ did show haemolytic crisis and died. It is suggested that management, transport stress together with high concentrated intake are factor related with the development of the haemolytic crisis. In the second, lower serum level of AST were found and lost of sheep with CCP sign were not observed. It is suggested that the serum level of AST is a helpful tool to early detection of haemolytic crisis due to CCP in sheep.
\end{abstract}

Keywords: copper, sheep poisoning, aspartate aminotransferase.

\section{Introdução}

Os ovinos armazenam cobre no fígado mais facilmente que outras espécies, sendo normal encontrar 10 a $50 \mathrm{mg} / \mathrm{kg}$ por peso de fígado fresco (Buck e Osweiler, 1981. Quando este valor alcança $150 \mathrm{mg} / \mathrm{kg}$ ou mais, o animal está predisposto a apresentar a crise hemolítica, que caracteriza clinicamente a intoxicação por cobre.

Hidiroglou et al. (1984), durante uma epidemia, estudaram modelos de excreção de cobre depois do tratamento com molibdato de amônia e sulfato de sódio ou penicilamina em 55 ovinos, revelando a possibilidade de diminuir os niveis de cobre, no fígado, dos animais tratados. No mesmo estudo concluíram, também, sobre a utilidade da dosagem da AST (Aspartato Transaminase) para diagnosticar e monitorar ani- mais prestes a apresentar sintomas de crise hemolítica decorrente da ICC (Intoxicação Crônica por Cobre).

Humphries et al. (1988) demonstraram que os niveis sangüíneos de aspartato transaminase (AST) e bilirrubina diminuíram, depois da administração de tetratiomolibdato de amônia, em ovelhas intoxicadas por cobre e, em uma semana, aproximadamente, os valores voltaram ao normal.

Casos de ICC foram descritos no Rio Grande do Sul (RS), por Ribeiro et al. (1985), que detectaram elevados níveis de cobre nas vísceras de ovinos, que ingeriram rações com altos níveis de cobre.

Escamilla e Martínez (1986), em quatro surtos de ICC em ovinos encontaram níveis séricos da AST superiores a 410 $\mathrm{UI} / \mathrm{I}$ em animais intoxicados com alimento concentrado, contendo esterco de galinhas.

\footnotetext{
* Professora da Faculdade de Veterinária da Universidade Federal do Rio Grande do Sul. Av. Bento Gonçalves, 9090. CEP 90540-000 .Porto Alegre, RS. E-mail: roselim@adufrgs.ufrgs.br

** Médico-veterinário. Rua São Carlos, 1231. CEP 90220-121. Porto Alegre, RS. E-mail: amato@cpov.net
} 
O aumento dos níveis séricos da AST, durante o desenvolvimento da ICC provocada experimentalmente, em cordeiros, pode ser útil para medir a evolução da intoxicação, durante o tratamento.

Ross (1964) e Todd apud Thompson e Todd (1974) observaram que no soro dos animais há um aumento de atividade enzimática relacionada com o fígado, entre seis a oito semanas antes da crise hemolítica. O aumento da atividade enzimática no soro pode diminuir a níveis quase normais, entre uma a duas semanas antes da crise hemolítica, e voltar a subir com o aumento dos niveis de cobre no sangue, imediatamente antes e durante a crise hemolítica.

Kelleher e Ivan (1987) compararam a atividade da AST sérica e da dietilsucinato carboxilesterase, em ovelhas expostas a altas doses de cobre. Concluíram que a elevação da AST começa no sexto dia depois do tratamento com altas doses de cobre, enquanto a dietilsuccinato carboxilesterase começou a elevar-se dentro de sete dias após o recebimento do mesmo tratamento, indicando danos hepáticos evidentes.

O presente trabalho se propôs a identificar, por métodos bioquímicos, aqueles ovinos que, ao ingressarem no Parque de Exposições Assis Brasil, se encontravam em vias de desencadear crise hemolítica, decorrente da intoxicação por cobre, agravada pelo estresse do transporte para a Feira.

\section{Material e métodos}

\section{Coleta das amostras e dosagens de AST}

Através de questionário, cadastraram-se, ao dar entrada no parque de exposições, no primeiro ano, 62 ovinos de diversas raças: Texel, lle de France, Hampshire Down, Romney Marsh e Border Leicester, pertencentes a 16 propriedades rurais. No segundo ano, três propriedades do grupo pesquisado no primeiro ano não compareceram e 48 animais foram cadastrados.

Foram coletadas amostras de sangue, por punção da veia jugular, usando-se tubos com vácuo, de $5 \mathrm{ml}$, e agulhas descartáveis $40 \times 10$. O sangue colhido foi deixado coagular à temperatura ambiente, para obtenção do soro. Os frascos com soro foram colocados em recipientes com gelo fundente e enviados ao laboratório para dosagem da concentração de AST utilizando fotômetro de reflexão compacto Reflotron $®$ (Mannheim Boehringer) utilizando-se fitas magnéticas.

Todos os animais foram acompanhados durante 14 dias, após a coleta de sangue, com visitas e exames clínicos, observando-se a temperatura retal, apetite, sede, aspecto e volume da urina, aspecto das fezes e das mucosas.

Os animais que morreram durante a exposição foram necropsiados e fragmentos de fígados e rins foram fixados em solução de formol a $10 \%$, e após fixação, por um período mínimo de 48 horas, foram desidratados, corados pela técnica de hematoxilina \& eosina (Luna, 1968), e examinados ao microscópio óptico. Foi realizada, também, a coloração pelo ácido rubeânico, segundo método de Uzman (Luna, 1968). Essa técnica revela a presença de grânulos positivos, para 0 cobre, nos tecidos coletados.

A pesquisa de cobre nas visceras (fígado e rim) foi executada segundo técnica de Buck, 1969. As amostras foram previa- mente secas em estufa a $60^{\circ} \mathrm{C}$ e digeridas em bomba de Tolg com ácido nítrico a $150^{\circ} \mathrm{C}$ por duas horas. Após, foram analisadas por espectrofotometria de absorção atômica em chama de ar-acetileno.

\section{Análise estatística}

Os niveis de AST e cobre foram analisados mediante análise de variância em um modelo fatorial, considerando-se como fatores os dois anos e as raças (lle de France e Texel). A diferença entre os anos, para todas as raças, foi avaliada pelo teste $t$.

Foi empregada a Análise de Correlação Linear Simples entre a AST e o peso. O nível de significância adotado foi de $5 \%$. Os dados foram analisados com o programa Stata, versão 3 .

\section{Resultados}

Dos 62 animais pesquisados no primeiro ano, cinco deles desenvolveram a crise hemolítica e morreram durante a Exposição. Anorexia e inapetência foram os primeiros sinais observados, seguidos de depressão, debilidade, mucosas ictéricas e urina escura. Em 48 horas após o aparecimento destes sinais e sintomas, todos os animais morreram. Icterícia generalizada foi observada em todas as necropsias e o exame histopatológico mostrou lesões compatíveis com intoxicação crônica por cobre. Os níveis médios de cobre no fígado e rins dos animais foi respectivamente 1642 e $305 \mathrm{mg} /$ $\mathrm{kg}$. A ausência de aumento da temperatura e a falta de resposta à antibioticoterapia descartaram possiveis casos de leptospirose. Por outro lado, o quadro de necropsia não foi compativel com enterotoxemia.

No segundo ano, não ocorreram óbitos, durante a Exposição, nos 48 animais das propriedades que faziam parte da pesquisa.

\section{Niveis de aspartato transaminase (AST)}

$\mathrm{Na}$ Tabela 1 registram-se os níveis séricos enzimáticos de AST, nos dois anos da pesquisa.

Tabela 1: Valores de AST (aspartato transaminase) em ovinos de corte de diversas raças examinados

Valores de AST sérico (UI/I)

\begin{tabular}{cccccc} 
& & & & \multicolumn{2}{c}{ Amplitude } \\
Ano & $N$ & Média & Desvio-padrão & $\begin{array}{c}\text { Limite } \\
\text { Inferior }\end{array}$ & $\begin{array}{c}\text { Limite } \\
\text { Superior }\end{array}$ \\
\hline & & & & & \\
\hline & 62 & 339,34 & 265,83 & 33 & 1200 \\
II & 48 & 274,00 & 232,78 & 83 & 1000 \\
\hline
\end{tabular}

O teste t revelou que não há diferença $(p>0,05)$ entre os valores médios nos níveis enzimáticos nos animais estudados, apesar da diminuição observada no segundo ano. 
Na Tabela 2 observam-se os valores médios da AST no primeiro ano, nos animais que não desencadearam a crise hemolítica, e a média de AST dos animais que morreram após apresentarem o quadro da crise hemolítica.

Tabela 2: Valores de aspartato transaminase (AST) sérico de 62 ovinos, do tipo carne, conforme a evolução, expostos no primeiro ano

\section{Valores de AST sérico (UI/I)}

\begin{tabular}{|c|c|c|c|c|c|}
\hline \multirow[b]{2}{*}{ Característica } & \multirow[b]{2}{*}{$N$} & \multirow[b]{2}{*}{ Média } & \multirow[b]{2}{*}{$\begin{array}{l}\text { Desvio- } \\
\text { padrão }\end{array}$} & \multicolumn{2}{|c|}{ Amplitude } \\
\hline & & & & $\begin{array}{l}\text { Limite } \\
\text { inferior }\end{array}$ & $\begin{array}{c}\text { limite } \\
\text { superior }\end{array}$ \\
\hline Sobreviventes & 57 & 278,68 & 159,96 & 33 & 903 \\
\hline Óbitos & 5 & 1030,80 & 263,33 & 600 & 1200 \\
\hline
\end{tabular}

Os dados mostram que 54 animais tinham AST menor que $600 \mathrm{UI} / \mathrm{I}$ e destes, um morreu. Oito animais apresentaram AST maior que este valor, sendo que $50 \%$ (4) morreram. A taxa de razão de chances é de $53(p=0,002)$. Os ovinos com valores de AST superiores a $600 \mathrm{UI} / \mathrm{l}$ têm 53 vezes mais chances de morrer do que os ovinos com AST menor que 600 UI/I.

$\mathrm{Na}$ Tabela 3, registram-se os niveis séricos de AST nas raças lle de France e Texel, nos dois anos da pesquisa.

Tabela 3 : Níveis de aspartato transaminase (AST) em ovinos das raças lle de France e Texel, examinados

\begin{tabular}{|c|c|c|c|c|c|c|}
\hline \multirow[b]{3}{*}{ Raça } & \multicolumn{6}{|c|}{ Valores de AST sérico (UI/I) } \\
\hline & \multicolumn{3}{|c|}{ Ano 1} & \multicolumn{3}{|c|}{ Ano II } \\
\hline & $\mathrm{N}$ & Média & $\begin{array}{l}\text { Desvio- } \\
\text { padrão }\end{array}$ & $N$ & Média & $\begin{array}{l}\text { Desvio- } \\
\text { padrão }\end{array}$ \\
\hline lle de France & 43 & 349,26 & 303,83 & 35 & 307,73 & 263,57 \\
\hline Texel & 12 & 318,83 & 95,65 & 9 & 178,48 & 664,62 \\
\hline
\end{tabular}

Pela análise de variância verificou-se interação positiva entre ano e a raça $(p=0,0065)$, sendo que, nos animais da raça lle de France, os níveis de AST mantiveram-se altos nos dois anos $(p=0,27)$. Nos ovinos Texel, houve uma diminuição significativa ( $p=0,0017)$, em 1994 .

Não houve correlação $(r=-0,14 ; p=0,167)$ entre os níveis de AST sérico e o peso dos animais para ambos os sexos. Também os níveis séricos de AST não diferiram $(p>0,05)$, entre as idades, nos dois anos de pesquisa.

\section{Discussão}

No presente trabalho foi usada a dosagem de AST para detectar, precocemente, animais em vias de desencadear crise hemolítica, o que ocorreu, no primeiro ano, em cinco animais que apresentavam, dois a três dias antes do aparecimento dos sintomas e, anterior ao óbito, níveis de AST superiores a $600 \mathrm{UI} / \mathrm{l}$. Sabe-se que a atividade da enzima começa a aumentar antes da crise hemolítica, atingindo seu ponto máximo uma semana antes da ocorrência da crise (Ross, 1966).

Os teores médios de AST $(1030,80 \pm 263,33 \mathrm{UI} / \mathrm{I})$ no sangue dos ovinos, que morreram durante o período experimental, são semelhantes aos reportados por Ross (1964), MacPherson e Hemingway (1969) e Kelleher e Ivan (1987), que estudaram a validade das análises bioquímicas no sangue, para detecção precoce da crise hemolítica e diagnóstico da intoxicação crônica por cobre em ovinos.

Ribeiro et al. (1995) encontraram níveis da enzima inferior aos do presente trabalho utilizando o mesmo método de dosagem da AST e em rebanho de ovinos da raça lle de France, intoxicados por cobre, ao pastorear por quatro semanas em pomares aspergidos com sulfato de cobre, onde o nível deste elemento na pastagem era de $60 \mathrm{mg} / \mathrm{kg}$,

Supõe-se que a média da AST foi inferior devido ao menor tempo de exposição ao cobre. O nivel de cobre ingerido diminuiu após as quatro semanas, enquanto, neste trabalho, as doses aumentavam com a proximidade da realização da Feira.

Hidiroglou et al.(1984), mediram a AST de duas em duas semanas durante o tratamento e observaram o aumento da enzima até 2300 UF (Unidades Frankel) (aproximadamente 1104 UI/I usando-se fator de correção UF x 0,48 = UI/l; Kaneko, 1989). Trabalhando nas mesmas condições (animais estabulados) do presente trabalho, os autores consideraram os niveis de cobre no fígado superiores a $800 \mathrm{mg} / \mathrm{kg}$ e o estresse como sério risco para o desenvolvimento da crise hemolítica. Após tratamento, 49 de 55 ovelhas apresentavam AST inferior a 220 UF (aproximadamente 105,6 UI/I).

Os autores ressaltam a utilidade da dosagem desta enzima para monitorar adequadamente a intoxicação crônica por cobre em ovinos.

Escamilla e Martínez (1986) encontraram valores de AST superiores a $410 \mathrm{UI} / \mathrm{I}$. Estes níveis relativamente baixos da enzima, encontrados pelos autores, talvez tenham ocorrido pelo fato destes animais se encontrarem a campo, com pasto verde disponível, no qual o aporte de molibdênio, apesar de desequilibrado, modificaria os resultados. Os autores não esclareceram em que fase a enzima foi medida, se antes ou após o aparecimento dos sintomas.

Os dados de AST, inferiores aos encontrados neste trabalho (150 UI/I) por Humphries et al.(1986), podem ser devido ao fato de que os autores, como estavam testando tratamentos, esperaram o desencadeamento dos sintomas para medir a atividade da enzima, visando demonstrar que, com o tratarnento, os níveis diminuiriam.

Estudos de Doxey (1985) confirmam que níveis superiores a 500 UI/I são encontrados em casos de lesão hepática aguda. 
Kaneko (1989) registra que os níveis séricos normais de aspartato transaminase para ovinos são de $307 \pm 43 \mathrm{UI} / \mathrm{l}$. No presente trabalho, os dados da Tabela 2 mostram que os ovinos que sobreviveram apresentavam médias de 278,68 $\mathrm{UI} / \mathrm{I}$, enquanto os que morreram revelaram níveis entre $600 \mathrm{e}$ $1200 \mathrm{UI} / \mathrm{l}$.

Os valores séricos enzimáticos, relatados neste trabalho (Tabela 1) são pioneiros neste estado, quanto à realização em animais clinicamente sadios, estabulados e preparados para Feiras/Exposição.

Em trabalhos anteriores, as intoxicações eram experimentais ou em surtos, quando os sintomas já estavam presentes ou alguns animais já estavam mortos. Outro fator que diferencia este trabalho é o estresse da viagem a que foram submetidos os animais.

Nos animais da raça Texel, no presente trabalho, os níveis enzimáticos da AST diminuíram no segundo ano. Atribuemse estas reduções, ao fato de que durante a feira no primeiro ano, por ocasião do preenchimento dos formulários da pesquisa, os proprietários, tratadores e médicos-veterinários foram orientados a aumentar a alimentação com pasto verde,

\section{Referências}

BUCK, W.B.; OSWEILER, G.D. Toxicología veterinaria clínica y diagnóstica. Zaragoza: Editorial Acribia, 1981, p. 369-394.

DOXEY, D.L. Patologia clínica e métodos de diagnóstico. 2. ed. Rio de Janeiro: Interamericana, 1985. p. 48-60, 176-177, 201,232.

ESCAMILLA, R.M.G.; MARTÍNEZ, R.R. Frecuencia y aspectos diagnósticos de la intoxicación cúprica de ovinos en México, Vet. México, v. 17, p. 209-211, 1986.

HIDIROGLOU, M.; HEANEY D.P.; HARTIN, K.E. Copper poisoning in a flock of sheep. Copper excretion patterns after treatment with molybdenum and sulfur or penicillamine. Can. Vet. J. v. 25, p. 377-382, 1984.

HUMPHRIES, W.R.; MILLS, C.F.; GREIG, A. ROBERTS, L.; INGLIS, D.; HALLIDAY, G.J. Use of ammonium Tetrathiomolybdate in the treatment of copper poisoning in sheep. Vet Rec. London, v. 119, p. 596-598, 1986.

KANEKO, J.J. Clinical Biochemistry of Domestic Animals. 4. ed. Davis: Academic Press, 1989, p. 881-887. de boa qualidade, principalmente de gramíneas frescas. Pôdese, no segundo ano, conferir o atendimento desta recomendação, através de questionários que foram aplicados.

\section{Conclusões}

A atividade da enzima, aspartato transaminase, no sangue de ovinos, é um indicador da lesão hepática na intoxicação crônica por cobre e no desencadeamento da crise hemolítica. A sua medida é útil e pode ser utilizada para prever 0 surgimento do quadro clínico.

A utilização de métodos bioquímicos para o diagnóstico da crise hemolítica em ovinos viabiliza a prevenção que evita a perda destes animais.

A dosagem de AST reúne a vantagem da simplicidade de realização com o baixo custo operacional.

Ovinos tipo carne, preparados para Feiras/Exposições ou mantidos com dieta de concentrados podem ser monitorados através da medida da AST, visando prevenir o aparecimento da crise hemolítica.

KELLEHER, C.A.; IVAN, M. Diethylsuccinate carboxylesterase activity in sheep poisoned by Copper. J.Comp.Path., v. 97, p. 329-333, 1987.

MaCPERSON, A.; HEMINGWAY, R.G. The relative merit of various blood analyses and liver function tests in giving an early diagnosis of chronic copper poisoning in sheep. Br.Vet.J., London, p. 125-213, 1969.

RIBEIRO, L.A.O.; RODRIGUES, N.C.; NARDIN, N.S. Intoxicação crônica pelo cobre no Rio Grande do Sul; histologia e toxicologia In: CONGRESSO ESTADUALDE MEDICINA VETERINÁRIA, 9., 1985, Santa Maria, RS. Anais...Santa Maria, 1985. p. 71.

RIBEIRO, L.A.O.; PIRES NETO, J.A.S.; RODRIGUES, N.C.; FALLAVENA, L.C.B. Intoxicação crônica por cobre em ovinos mantidos em pomar de macieiras. Pesq. Vet. Bras., Rio de Janeiro, v. 15, n. 1, p. 15-17, 1995. ROSS, D.B. Chronic copper poisoning in lambs. Vet. Rec., London, v. 76, n. 32, p. 875-876, 1964

ROSS, D.B. The diagnosis, prevention and treatment of chronic copper poisoning in housed lambs. British Vet. J. London, v. 122, p. 279-284, 1966.

THOMPSON, R.H.; TODD, J.R. Muscle damage in chronic copper poisoning of sheep. Res. Vet. Sci. v. 16, p. 97-99, 1974. 